\title{
Protective ventilation improves gas exchange and affects metabolic response after major abdominal surgery
}

Ilyina YY, Rodionova LN, Ushakov AA, Fot EV, Kuzkov WV, Kirov MY

Department of Anaesthesiology and Intensive Care Medicine, Northern State Medical University, Arkhangelsk, Russian Federation

\section{Background \& Goal}

In major abdominal surgery, protective perioperative ventilation with low tidal volumes has a potential to improve postoperative outcomes and reduce the risk of pulmonary complications. ${ }^{1}$ In addition, in experimental settings, hypercapnia could beneficially affect tissue perfusion and organ function. ${ }^{2}$ The goal of our study was to assess the effects of the protective ventilation with low tidal volume $\left(\mathrm{V}_{\mathrm{T}}\right)$ either alone or combined with moderate permissive hypercapnia in major abdominal surgery.

\section{Methods}

The study protocol and informed consent were approved by the Ethical Committee of the Northern State Medical University.

Sixty patients ( 28 females / 32 males, aged 54 (45-60) yrs) scheduled for major pancreatoduodenal and/or biliary surgery (mostly, pancreatic cancer) with expected duration exceeding $2 \mathrm{hrs}$ were included into a singlecentre prospective randomised study.

The patients were randomised to three groups receiving either routinely high $\mathrm{V}_{\mathrm{T}}$ $(10 \mathrm{~mL} / \mathrm{kg}$ of predicted body weight (PBW): the HVT group, $n=20)$ or low $\mathrm{V}_{\mathrm{T}}(6 \mathrm{~mL} /$ kg PBW: the LVT group, $n=20)$. An additional group with low $\mathrm{V}_{\mathrm{T}}$ combined with moderate permissive hypercapnia $\left(\mathrm{V}_{\mathrm{T}} 6\right.$ $\mathrm{mL} / \mathrm{kg} \mathrm{PBW}$ and $\mathrm{PaCO}_{2} 45-55 \mathrm{~mm} \mathrm{Hg}$ : the LVT $+\mathrm{HC}$ group, $n=20)$. In all groups PEEP of $4 \mathrm{~cm} \mathrm{H} \mathrm{O}$ was set. All interventions were performed using combined volatile (sevoflurane) and epidural anaesthesia. Haemodynamic parameters and gas exchange were registered during the surgery and up to 72 hrs of the postoperative period. We also analysed the incidence of the postoperative complications during the ICU stay.

Data are presented as median $\left(25^{\text {th }}-75^{\text {th }}\right.$ percentiles). Intergroup comparisons are made with Mann-Whitney $U$-test and $\chi^{2}$-test. A $p$ value below 0.05 was regarded as statistically significant.

\section{Results \& Discussion}

We did not find any significant baseline differences between the groups except for smoking incidence, that was higher in the HVT group (Table 1). The duration of postoperative ventilation was not different between the groups. The 28-Days mortality was $5 \%(n=3)$ and the incidence of the postoperative complications was $40 \%(n=24)$.

\begin{tabular}{|c|c|c|c|}
\hline Data & HVT & LVT & LVT + HC \\
\hline Age, yrs & $64(61-70)$ & $64(58-67)$ & 0.62 \\
\hline Weight, kg & 80 (71-94) & $78(70-86)$ & 0.70 \\
\hline Gender (F / M) & $8 / 12$ & $11 / 9$ & $9 / 11$ \\
\hline Duration of surg., $\min$ & $160(135-250)$ & $190(138-234)$ & $225(180-264)$ \\
\hline Duration of $\mathrm{CMV}$, min & $360(270-525)$ & 370 (265-499) & $400(295-473)$ \\
\hline LOS ICU, hrs & $44(24-85)$ & $43(22-68)$ & $45(27-76)$ \\
\hline LOS hospital, days & $42(25-51)$ & $28(21-38)$ & $31(26-41)$ \\
\hline Smoking history, $\mathbf{n}(\%)$ & $6(30)^{*}$ & $14(70)$ & $13(65)$ \\
\hline Complications, n (\%) & $11(55)^{*}$ & $5(25)$ & $8(40)$ \\
\hline
\end{tabular}
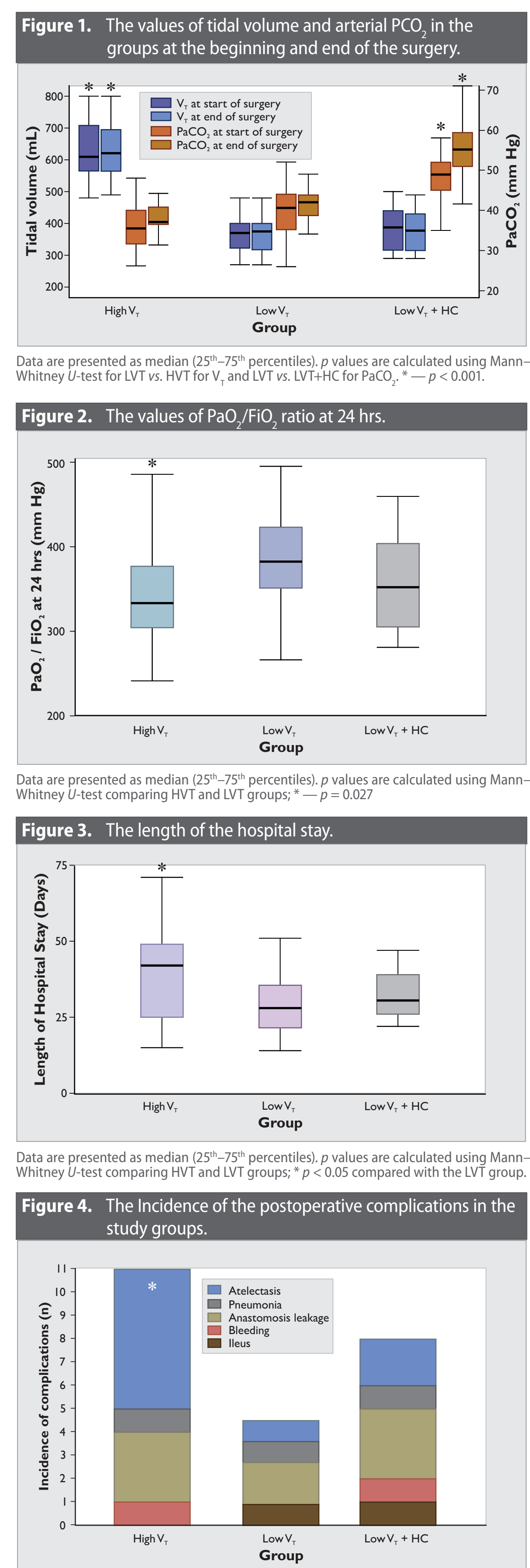

The values of $\mathrm{V}_{\mathrm{T}}$ and $\mathrm{PaCO}_{2}$ at the start and completion of the surgery for HVT, LVT, and LVT+HC groups are presented in Figure 1. Compared with the HVT group, $\mathrm{PaO}_{2} /$ $\mathrm{FiO}_{2}$ ratio at $24 \mathrm{hrs}$ postoperatively was higher in the LVT group: 333 (301-381) vs. $382(349-423) \mathrm{mm} \mathrm{Hg}(p=.027)$, but not in the LVT+HC group (Figure 2). Notably, the transient improvement of the postoperative oxygenation was achieved despite the higher incidence of smoking in the LVT group compared with the HVT group (Table 1).

The length of hospital stay was significantly longer in the HVT group compared with the LVT group (Figure 3), that can be related to the higher incidence of the postoperative complications, particularly, atelectases (Figure 4). We found no differences in the incidence of the complications between the HVT and the LVT+HC groups.

By the end of the surgery, arterial lactate concentration was decreased in the LVT+HC group compared with the LVT group: 0.7 (0.5-1.0) vs. $1.5(1.0-3.1) \mathrm{mmol} / \mathrm{L}$, respectively $(p<.02)$. However, arterial bicarbonate excess was worse in the LVT+HC group compared with the LVT group at 6 hrs postoperatively: $-6.1(-5.8$ to -7.4$)$ and $-5.1(-6.1$ to -3.4$) \mathrm{mmol} / \mathrm{L}$, respectively $(p<$ $.001)$.

\section{Conclusions}

Preventive reduction of tidal volume in major pancreatoduodenal surgery results in improved postoperative oxygenation, reduced rate of complications, namely atelectases, and shortened length of the hospital stay.

The combination of low tidal volume and moderate permissive hypercapnia might exert some metabolic effects but does not add any substantial benefits to the outcome and organ function, and needs further studies.

\section{Acknowledgements}

We appreciate the assistance of Maria $\mathrm{M}$. Sokolova, MD, Andrey A. Papko, MD, and Maria A. Feoktistova, MD.

\section{References}

1. Futier E, Constantin JM, Paugam-Burtz C, et al. A trial of intraoperative low-tidal-volume ventilation in abdominal surgery. N Engl J Med 2013; 369: 428-37

2. Masterson C, Otulakowski G, Kavanagh BP. Hypercapnia: clinical relevance and mechanisms of action. Curr Opin Crit Care 2015; 21: 7-12.

Corresponding author: Yana Y. Ilyina, MD E-mail: yana.ilyina@mail.ru 